\title{
Suppressive role of diallyl trisulfide in the activated platelet-mediated hematogenous metastasis of MDA-MB-231 human breast cancer cells
}

\author{
YUPING LIU ${ }^{1,2^{*}}$, YANG ZHAO ${ }^{1,2^{*}}$, YINGYU WANG ${ }^{1,2^{*}}$, PINGTING ZHU ${ }^{1,2}$, ZHONGHONG WEI $^{1,2}$, \\ SILIANG WANG ${ }^{1,2}$, LI TAO $^{1,2}$, ZHAOGUO LIU $^{1,2}$, HONGYAN WU $^{1,2}$, XIAOBO SHENG $^{1,2}$ and YIN LU $U^{1,2}$ \\ ${ }^{1}$ Department of Pharmacology, College of Pharmacy, Nanjing University of Chinese Medicine; \\ ${ }^{2}$ Jiangsu Key Laboratory for Pharmacology and Safety Evaluation of Chinese Materia Medica, \\ Nanjing University of Chinese Medicine, Nanjing, Jiangsu 210023, P.R. China
}

Received January 5, 2016; Accepted February 16, 2017

DOI: $10.3892 / \mathrm{ijmm} .2017 .2953$

\begin{abstract}
Accumulating evidence has indicated that garlic consumption may reduce the risk of developing several types of cancer, and extensive studies have revealed the effects of its bioactive component, diallyl trisulfide (DATS), on the proliferation and apoptosis of tumor cells. The present study was undertaken to examine whether DATS affects hematogenous metastasis. In view of the dynamic crosstalk interplayed by tumor cells and platelets in hematogenous metastasis, we attempted to demonstrate the role of DATS in the metastatic behavior of MDA-MB-231 human breast cancer cells, which were co-incubated with activated platelets. Indeed, our data indicated that DATS significantly blocked platelet activation and aggregation induced by platelet-activating factor (PAF), and decreased the production of thromboxane $\mathrm{B} 2$ (TXB2). It was also found that DATS suppressed the migration and invasion of MDA-MB231 cells in the presence of platelets activated by PAF in vitro in a dose-dependent manner. Furthermore, our results revealed thaat the release of activated TGF- $\beta 1$ in the platelet-tumor cell system was markedly attenuated by DATS. Therefore, our findings strongly suggest that the diverse pharmacological activities of DATS are at least partially reflected by the interruption of the activated platelets-mediated metastasis of breast cancer cells.
\end{abstract}

\section{Introduction}

Metastasis is the leading cause of cancer-related mortality (1). The regulation of metastasis by tumor cells does not occur

Correspondence to: Professor Yin Lu, Department of Pharmacology, College of Pharmacy, Nanjing University of Chinese Medicine, 138 Xianlin Avenue, Nanjing, Jiangsu 210023, P.R. China E-mail: profyinlu@163.com

${ }^{*}$ Contributed equally

Key words: breast cancer, platelet, transforming growth factor- $\beta 1$, diallyl trisulfide, metastasis autonomously, but it instead involves a dynamic crosstalk between tumor cells and host cells, which is increasingly recognized as a key indicator of malignant progression (2). There is a substantial amount of data and information available support the hypothesis that platelets play a critical role in promoting hematogenous tumor metastasis. The link between platelets and cancer progression was first proposed in the mid-19th century by Trousseau, who diagnosed himself and his patients with excessive blood clotting caused by an occult carcinoma that led to the inflammation of blood vessels (3). There are long-term clinical data to indicate that the platelet count and blood hypercoagulable state may be important prognostic factors in many types of cancer, including breast cancer (4), cervical carcinoma $(5,6)$ and lung cancer (7). In the circulation, platelets released from megakaryocytes bind to circulating tumor cells, forming platelet-cell microemboli. This type of microemboli has been shown to enhance tumor cell migration and motility, allow tumor cells to evade immune cell monitoring and blood flow shear destruction and promote angiogenesis (8).

Among the multitude of different signaling molecules found in the blood, transforming growth factor- $\beta$ (TGF- $\beta$ ) is known to aggregate metastasis by promoting epithelial-mesenchymal transition (EMT) and the invasiveness of primary carcinomas (9). TGF- $\beta 1$, an ubiquitous cytokine, induces cancer cells to proliferate and promotes them to form an invasive phenotype $(10,11)$. TGF- $\beta$ ligands are secreted from cells in three isoforms (TGF- $\beta 1$, TGF- $\beta 2$, TGF- $\beta 3$ ), with the latency associated protein (LAP), which makes these isoforms inactive. This latent TGF- $\beta$ complex contains another protein known as the latent binding protein, which assists in the extracellular localization of the latent complex. TGF- $\beta 1$ is activated in vivo by the proteolytic cleavage of LAP at a low $\mathrm{pH}$ or from interactions with other proteins, such as thrombospondins and $\alpha v \beta 6$ integrin (12). Active TGF- $\beta 1$ is released as a dimer and is involved in numerous regulatory activities that influence development, tissue repair, immune defense, inflammation and tumorigenesis (13). Released TGF- $\beta 1$ binds to the TGF $\beta$ RI/ II complex and the Smad signaling pathway is activated by the phosphorylation and activation of downstream pathways, 
including mitogen-activated protein kinase (MAPK) (14), nuclear factor (NF)- $\mathrm{B}$ (15) and Rho-GTPase (16), which regulate tumor extracellular matrix remodeling, inflammatory responses and angiogenesis that promote tumor metastasis $(17,18)$. Clinical data have indicated that patients with various types of cancer, such as breast cancer, prostate cancer and gastric cancer have elevated blood levels of TGF- $\beta 1$, and its local expression level has been shown to positively correlate with tumor size, histological grade and the number of metastases (19-22). The development of therapies that target platelet-mediated TGF- $\beta 1$ in the tumor microenvironment may provide promising treatments for preventing tumor metastasis.

Chemicals in the diet are increasingly being recognized as essential factors for cancer chemoprevention and treatment (23). The identification of new drugs from plants has a long and successful history. In particular, traditional Chinese medicine has been widely used for thousands of years to promote blood circulation for inhibiting tumor metastasis (24). Diallyl trisulfide (DATS) is a fat-soluble compound that is the major biological component of garlic - a commonly used remedy to promote blood circulation (25). It can be isolated, purified and obtained by chemical synthesis. Clinical studies have indicated that garlic has a strong effect on the coagulation system and can significantly inhibit the induction of platelet activation and aggregation by regulating a variety of active agents, including thrombin, adenosine diphosphate (ADP), platelet-activating factor (PAF) and collagen (26-28). Moreover, the use of garlic as a chemopreventive agent has gained interest in the field of cancer prevention and treatment $(29,30)$. Currently, studies on the antitumor activity of garlic have focused on the inhibition of tumor proliferation, blocking the cell cycle and inducing apoptosis; however, there have been relatively fewer investigations carried out into its role in tumor metastasis (31-34). Despite this situation, there are some preclinical studies that have indeed demonstrated that animals administered garlic have exhibited reduced rates of metastasis (35-37).

In this study, we examined the effects of DATS on activated platelet-induced tumor metastasis in vitro. Our data indicates that DATS suppresses breast cancer cells migration and invasion by inhibiting the release of TGF- $\beta 1$ in the platelet-tumor cell system.

\section{Materials and methods}

Chemicals and reagents. DATS/DADS/DAS (Helin Co., Ltd., China) was isolated from garlic extract (Helin Co., Ltd.) with the purity of $97 \%$ as determined by HPLC. It was dissolved at a concentration of $1 \mathrm{M}$ in $100 \%$ DMSO as a stock solution, stored at $-20^{\circ} \mathrm{C}$, and diluted with culture medium before each experiment to a final DMSO concentration of $0.1 \%$. IL-15 medium (Gibco, Invitrogen Life Technologies, Inc., Carlsbad, CA, USA) was supplemented with $2 \%$ penicillin/streptomycin. Heat-inactivated fetal bovine serum (FBS) was obtained from Sijiqing Biotech Co., Ltd. (Hanzhou, China). Human platelets were purchased from Blood Center of Jiangsu, China. Thromboxane B2 (TXB2) and 6-keto-PGF1 $\alpha$ radioimmunoassay (RIA) kits were purchased from Beijing North Institute of Biological Technology (Beijing, China). Transwell filter discs $(8 \mu \mathrm{m})$ for migration assay by Corning were from Fisher Scientific (Nepean, ON, Canada). Rat tail collagen was prepared by the Galenical Pharmacy Institute of Nanjing University of Chinese Medicine, Nanjing, China. Recombinant human TGF- $\beta 1$ protein was from PeproTech (Princeton, NJ, USA) and human TGF- $\beta 1$ neutralizing antibody was from R\&D Systems (Minneapolis, MN, USA).

Cell culture. The MDA-MB-231 human breast cancer cell line was obtained from the American Type Culture Collection (ATCC; Rockville, MD, USA) and was grown to a monolayer culture in IL-15 medium supplemented with $10 \%$ heat-inactivated FBS, penicillin/streptomycin at $37^{\circ} \mathrm{C}$ with $5 \% \mathrm{CO}_{2}$. The cells were not used $>15$ to 20 passages after the initiation of culture.

Blood collection. Freshly drawn venous blood from healthy volunteers was collected into $130 \mathrm{mM}$ aqueous trisodium citrate anticoagulant solution (9:1). The donors claimed to not have taken drugs known to interfere with platelet functions during 2 weeks prior to blood collection and gave their informed consent. This study was approved by the Ethics Commitee of Nanjing University of Chinese Medicine. Citrated blood samples were centrifuged at $150 \mathrm{rpm}$ for 15 min to obtain platelet-rich plasma, followed by a second centrifugation at $1,500 \mathrm{rpm}$ for $15 \mathrm{~min}$ to obtain platelet-poor plasma (used as a blank value).

Platelet aggregation assay. Dissolved DATS was prepared using a stock solution of $10 \mu \mathrm{M}$ DATS with PBS. In the next step, $50 \mu 1$ of the stock solution were incubated with $450 \mu \mathrm{l}$ of platelet-rich plasma for $5 \mathrm{~min}$. Platelet aggregation was then measured in a four-channel aggregometer (Chrono-Log Corporation, Havertown, PA,USA) using the turbidimetric method according to the manufacturer's instructions. Follwoing $5 \mathrm{~min}$ of pre-incubation at $37^{\circ} \mathrm{C}$, the platelets were stimulated by the addition of ADP $(10 \mu \mathrm{mol} / \mathrm{l}), \operatorname{PAF}(5 \mathrm{nmol} / \mathrm{l})$ or thrombin $(0.1 \mathrm{U})$. The extent of platelet aggregation was determined by the area under the aggregation curve from 0 to 5 min following exposure to the stimulants, the platelet aggregation rate was expressed as a percentage of the area value, and the full platelet aggregation was always expressed as $100 \%$. Due to the fact that DATS exerts a significant inhibitory effect on PAF-induced platelet aggregation, we therefore investigated the concentration-response curve of DATS from 0.01 to $10 \mu \mathrm{M}$.

RIA. The washed platelets $\left(3.0 \times 10^{8} / \mathrm{ml}\right)$, pre-incubated with DATS at $37^{\circ} \mathrm{C}$ for $30 \mathrm{~min}$, were treated with PAF $(5 \mathrm{nmol} / \mathrm{l})$ for $5 \mathrm{~min}$ at $37^{\circ} \mathrm{C}$. Incubation was terminated by the addition of $50 \mu \mathrm{M}$ indomethacin and $2 \mathrm{mM}$ EDTA, the mixture was centrifuged at $14,000 \mathrm{x}$ g for $2 \mathrm{~min}$ at $4^{\circ} \mathrm{C}$ and the TXB2 and 6-keto-PGF1 $\alpha$ contents of samples were determined using the $\left[{ }^{125} \mathrm{I}\right] \mathrm{TXB} 2$ and $\left[{ }^{125} \mathrm{I}\right] 6$-keto-PGF1 $\alpha$ RIA kits.

TGF- $\beta 1$ ELISA. TGF- $\beta 1$ levels were detected in the conditioned medium from tissue culture $(40 \mathrm{~h})$, washed platelets or platelet-rich plasma using the Quantikine TGF- $\beta 1$ immunoassay kit (R\&D Systems) following the manufacturer's instructions.

Westen blot analysis. Whole-cell lysates were prepared with RIPA buffer containing protease and phosphatase inhibitors. 
Nuclear and cytoplasmic cell extracts were prepared using the NE-PER Nuclear and Cytoplasmic Extraction kit (Thermo Fisher Scientific Inc., Rockford, IL, USA). Equal amounts of cell lysates $(50 \mu \mathrm{g})$ were loaded on 8 or $10 \%$ SDS-PAGE and transferred onto PVDF membranes. After the membranes were blocked, they were incubated with monoclonal antibodies against p-Smad, Smad (1:1,000; Cell Signaling Technology, Danvers, MA, USA), GPADH (1:5,000; Bioworld Technology, Louis Park, MN, USA) followed by incubation with horseradish peroxidase-conjugated IgGs (1:10,000; Bioworld Technology). Target proteins were developed with an ECL detection agent (Millipore, Braunschweig, Germany) and visualized with the ChemiDoc XRS system (Bio-Rad, Hercules, CA, USA).

Wound healing mobility assay. The MDA-MB-231 cells $\left(5 \times 10^{5}\right)$ were seeded into a 6-well plate and allowed to grow to a confluent monolayer in complete medium. The medium was replaced with serum-free medium containing $1 \times 10^{7}$ platelets treated with PAF $(5 \mathrm{nmol} / \mathrm{l})$ for $1 \mathrm{~h}$ at $37^{\circ} \mathrm{C}$. The monolayers were disrupted (i.e., wounded) with P200 micropipette tips and any cellular debris present was removed by washing with sterile PBS.

Cell monolayers were then incubated with the medium containing various concentrations of DATS for $24 \mathrm{~h}$ at $37^{\circ} \mathrm{C}$. Images of the exact wound areas were acquired using an inverted microscope (Zeiss, Jena, Germany) and the number of cells in the scraped zone of each well was counted at the indicated time points using an inverted microscope (Zeiss) (0 and $24 \mathrm{~h}$ after scraping). The number of cells in the scraped zone of each well was counted 3 times and the counts were averaged.

Boyden chamber migration assay. Cell motility was tested in a Transwell Boyden chamber (Corning Costar, Cambridge, MA, USA) using a polycarbonate filter ( $8 \mu \mathrm{m}$ pores). The MDA-MB-231 cells $\left(3 \times 10^{5}\right)$ resuspended in $90 \mu \mathrm{l}$ IL-15 medium medium containing various concentrations of DATS were carefully transferred into the upper chamber. The lower chamber was filled with $600 \mu 110 \%$ FBS medium containing $3 \times 10^{7}$ PAF-activated platelets to attract cells in the upper chamber. The Transwell Boyden chamber was then incubated at $37^{\circ} \mathrm{C}$ for $6 \mathrm{~h}$. After the gentle removal of the filter from the chamber, the cells on the upper side of the filter were removed by wiping with a cotton swab. The filter was fixed with $5 \%$ glutaraldehyde at $40^{\circ} \mathrm{C}$ for $10 \mathrm{~min}$ and stained with $0.1 \%$ crystal violet stain solution (c0121; Beyotime, Shanghai, China). The cells on the lower surface of the filter, which penetrated the pore of the filter, were fixed onto a glass slide. Cells in 5 randomly selected microscopic fields (using an inverted microscope; Zeiss) (magnification, x400) of the lower surface were counted. This experiment was performed independently 3 times.

Collagen invasion assay. In vitro invasion assay was performed under the same conditions as the Transwell chamber motility assay except that the upper surface of the filter was coated with rat tail collagen. Rat tail collagen was maintained in a stock solution of $5 \mathrm{mg} / \mathrm{ml}$ and stored at $-20^{\circ} \mathrm{C}$. The rat tail collagen was mixed with $10 \mathrm{X}$ IL-15 medium and $1 \mathrm{M} \mathrm{NaOH}$ at a ratio of 1.37:0.22:0.1 at $40^{\circ} \mathrm{C}$. A total of $70 \mu \mathrm{l}$ of the complex was then added to the upper chamber and incubated at $37^{\circ} \mathrm{C}$ for $30 \mathrm{~min}$. An additional $100 \mu \mathrm{l}$ of IL-15 medium was added to the surface of the collagen and was incubated at $37^{\circ} \mathrm{C}$ for a further $30 \mathrm{~min}$, after which the medium was removed. The MDA-MB-231 cells $\left(3 \times 10^{5}\right)$ in $90 \mu \mathrm{l}$ medium treated with various concentrations of DATS were carefully transferred onto the collagen in the upper chambers. The lower chamber was filled with $600 \mu \mathrm{l}$ medium supplemented with $10 \%$ FBS to attract cells in the upper chamber. Following $24 \mathrm{~h}$ of incubation at $37^{\circ} \mathrm{C}$, the filter of the chamber was gently removed and the cells on the upper side of the filter were wiped. The filter was then fixed with $5 \%$ glutaraldehyde at $4^{\circ} \mathrm{C}$ for $10 \mathrm{~min}$ and stained with $0.1 \%$ crystal violet staining solution. The stained cells were counted in 5 randomly selected microscopic fields (magnification, $\mathrm{x} 400$ ). This experiment was performed independently 3 times.

Statistical analysis. The results were analyzed using a two-tailed Student's t-test using SPSS 11.0 software (Aspire Software International, Leesburg, VA, USA) and thye results were considered significant between two samples at a value of $\mathrm{P}<0.05$.

\section{Results}

TGF- $\beta 1$ is critical for activated platelet-induced metastasis in vitro. To examine the effects of activated platelets on tumor cell migration and invasion, we used PAF as a platelet agonist. The MDA-MB-231 human breast cancer cells were incubated with activated platelets for $24 \mathrm{~h}$ and the levels of TGF- $\beta 1$ in the platelet-tumor cell system were measured by ELISA. The results revealed that the activated platelets rather than PAF or resting platelets (RP) promoted the release of TGF- $\beta 1$ in MDA-MB-231 cells (Fig. 1A and B). Moreover, the activated platelets induced the horizontal (Fig. 1C) and vertical migration (Fig. 1D and E) and invasion (Fig. 1F and G) of MDA-MB-231 cells, all of which were attenuated in the presence of the TGF- $\beta 1$ neutralizing antibody. These results indicate that only activated platelets have the potential to trigger the malignant biological behaviors of tumor cells and the release of TGF- $\beta 1$ plays an essential role in facilitating these malignant behaviors in the platelet-tumor cell system.

Release of TGF- $\beta 1$ in the activated platelet-tumor cell system is decreased by DATS. The number of sulfur atoms in allylsulfides is an important factor to determine the chemical and biological activities of garlic-derived organosulfides. As shown in Fig. 2A, DATS has more sulfur atoms compared with diallyl sulfide (DAS) and diallyl disulfide (DADS). In Fig. 1B, we demonstrated that MDA-MB-231 cells exposed to activated platelets stimulated by PAF secreted increased prometastatic factor TGF- $\beta 1$. To this end, various concentrations of DATS (0-20 $\mu \mathrm{M})$ and $10 \mu \mathrm{M}$ DADS/DAS were added to the activated platelet-tumor cell system and incubated for $24 \mathrm{~h}$ at $37^{\circ} \mathrm{C}$. It was found that DATS attenuated the activated TGF- $\beta 1$ level in the cell culture supernatant in a dose-dependent manner. However, $10 \mu \mathrm{M}$ DADS/DAS had no obvious effect on the release of TGF- $\beta 1$ (Fig. $2 \mathrm{~B}$ ). 

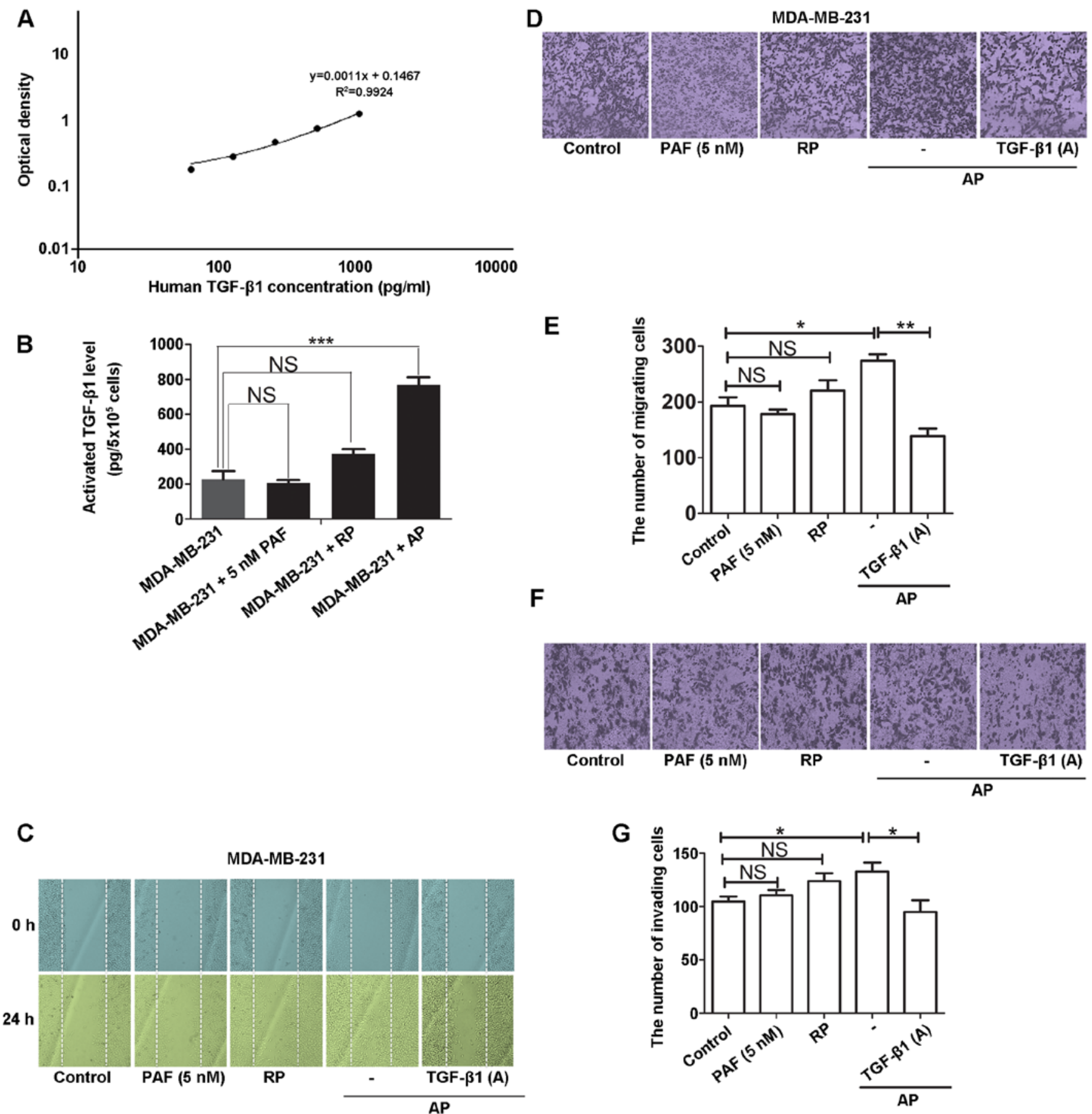

Figure 1. The release and function of transforming growth factor- $\beta 1$ (TGF- $\beta 1$ ) in the activated platelet-tumor cell system. (A and B) Concentrations of TGF- $\beta 1$ measured by ELISA in resting platelets, activated platelets and platelet-activating factor (PAF)-stimulated MDA-MB-231 cells. (C) Horizontal migration of MDA-MB-231 cells subjected to different treatments. Confluent MDA-MB-231 cells were scratched and incubated with $5 \mathrm{nM}$ PAF, resting platelets, activated platelets and $20 \mathrm{ng} / \mathrm{ml}$ recombinant human TGF- $\beta 1$ neutralizing antibody. ${ }^{* *} \mathrm{P}<0.01$ compared with the normal control. (D) Vertical migration of MDA-MB-231 cells with different treatments. MDA-MB-231 cells $\left(2 \times 10^{5}\right)$ were plated in the upper well of Transwell Boyden chamber, medium containing $3 \times 10^{7}$ PAF-activated platelets, $5 \mathrm{nM}$ PAF and $20 \mathrm{ng} / \mathrm{ml}$ recombinant human TGF- $\beta 1$ neutralizing antibody was added into the lower well. (E) Quantification of three-dimensional cell migration. (F) Invasion of MDA-MB-231 cells with different treatments. MDA-MB-231 cells were treated with PAF-activated platelets, $5 \mathrm{nM}$ PAF and $20 \mathrm{ng} / \mathrm{ml}$ recombinant human TGF- $\beta 1$ neutralizing antibody for $24 \mathrm{~h}$. ${ }^{*} \mathrm{P}<0.05$ and ${ }^{* *} \mathrm{P}<0.01$. (G) Quantification of MDA-MB-231 cell invasion. ${ }^{*} \mathrm{P}<0.05$. NS, not significant; $\mathrm{RP}$, resting platelets; AP, activated platelets.

DATS inhibits the activated platelet-induced migration and invasion of MDA-MB-231 cells by reducing the release of TGF- $\beta 1$. Since the level of TGF- $\beta 1$ was decreased following treatment with DATS, we hypothesized that the MDA-MB-231 cells stimulated with the activated platelets would yield a net decrease in metastatic potential when treated with DATS. Indeed, we found that $10 \mu \mathrm{M}$ DATS inhibited the horizontal (Fig. 2C) and vertical migration (Fig. 2D) and invasion (Fig. 2E) of MDA-MB-231 cells induced by activated platelets using wound healing and Transwell Boyden 
A<smiles>C=CCCSCCC=C</smiles>

(DAS)<smiles>C=CCCSSCC=C</smiles>

(DADS)<smiles>C=CCSSSCC=C</smiles>

(DATS)

B
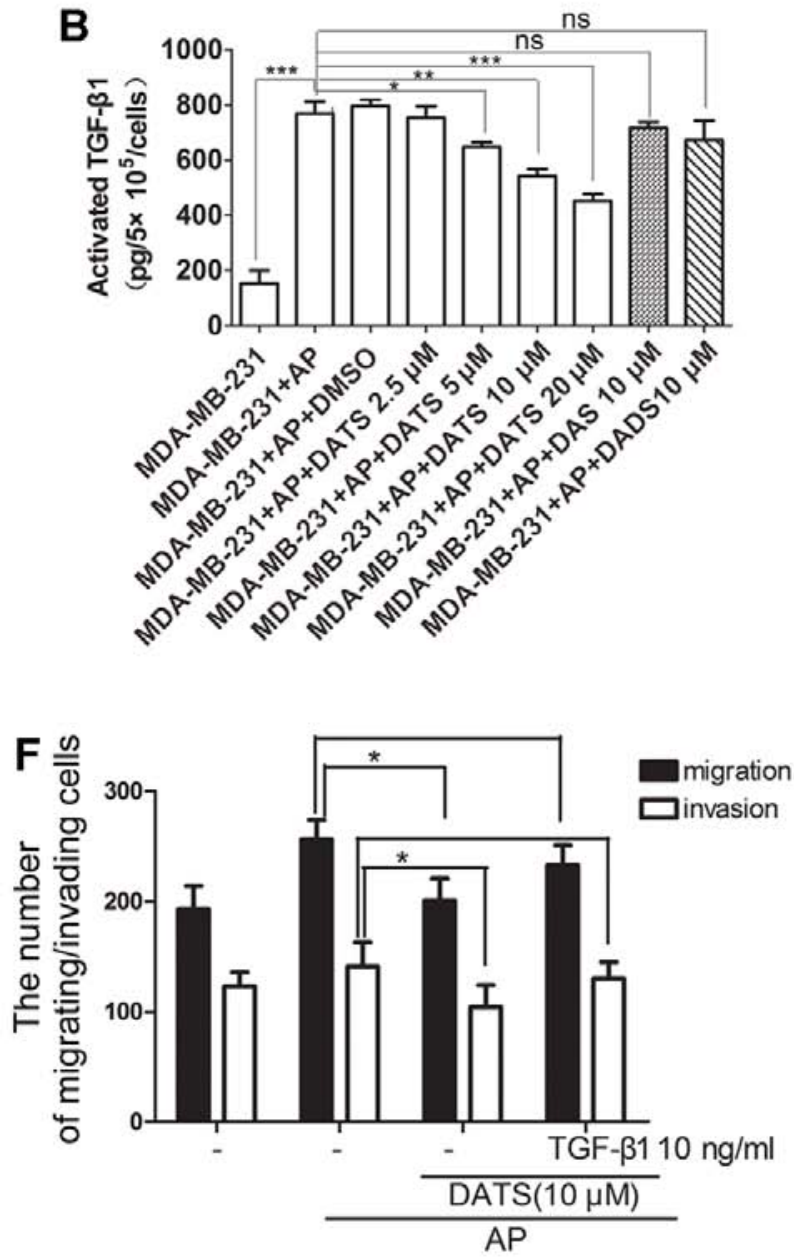

C

$\mathrm{Oh}$

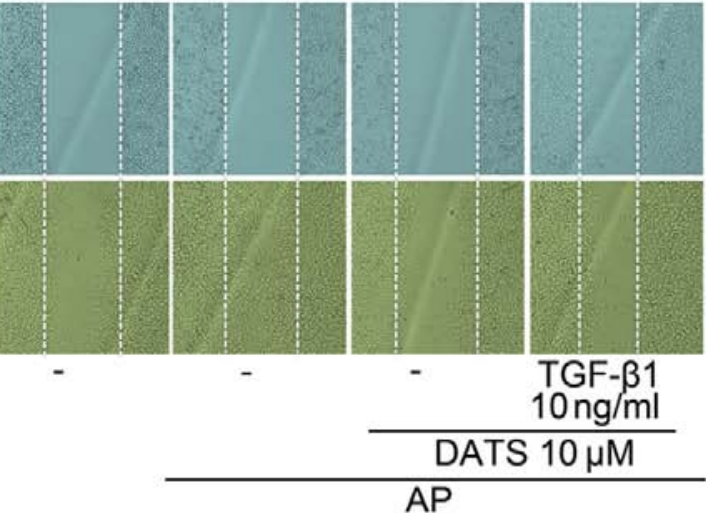

D

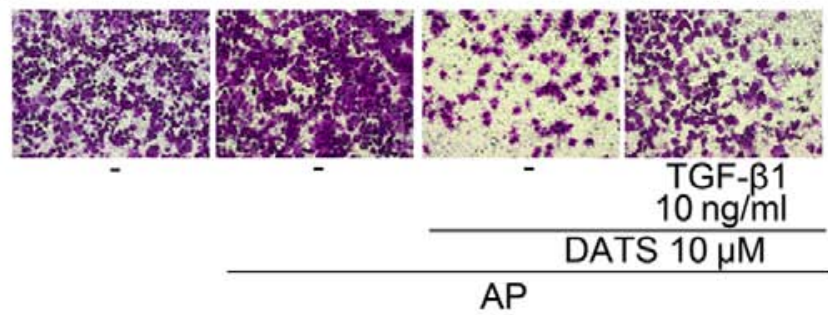

E
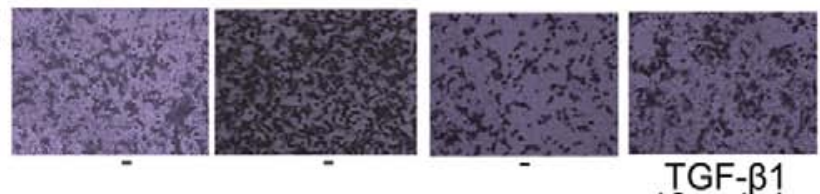

$10 \mathrm{ng} / \mathrm{ml}$

DATS $10 \mu \mathrm{M}$

AP

G p-Smad

Smad

GAPDH

Activated platelets

$\operatorname{DATS}(10 \mu \mathrm{M})$ -

TGF- $\beta 1(10 \mathrm{ng} / \mathrm{ml})$ -

Figure 2. Effects of garlic organic sulfides (OSCs) on the platelet-tumor cell system. (A) Structure of garlic liposolubility OSCs (DAS/DADS/DATS). (B) Concentration of activated transforming growth factor- $\beta 1$ (TGF- $\beta 1$ ) measured by ELISA in the conditioned medium of MDA-MB-231 cells incubated with activated platelets treated by different concentrations of DATS $(0-20 \mu \mathrm{M})$ and $10 \mu \mathrm{M}$ DAS/DADS. ${ }^{*} \mathrm{P}<0.05,{ }^{* * *} \mathrm{P}<0.01$ and ${ }^{* * *} \mathrm{P}<0.001$. ns, not significant. (C) Vertical migration of MDA-MB-231 cells. Monolayers of the cells incubated with platelet-activating factor (PAF)-activated platelets were scraped and treated with DATS $(10 \mu \mathrm{M})$ and recombinant human TGF- $\beta 1(20 \mathrm{ng} / \mathrm{ml})$, the cells in the denuded zone were photographed after indicated times $(0$ and $24 \mathrm{~h})$. (D) MDAMB-231 cell vertical migration was determined by measuring the ability of cells to pass through the filters. The cells incubated with $3 \times 10^{7}$ PAF-activated platelets were cultured in the upper well. Indicated concentrations of DATS and recombinant human TGF- $\beta 1(20 \mathrm{ng} / \mathrm{ml})$ were put in the upper wells and medium containing $10 \%$ fetal bovine serum (FBS) was added into the lower wells. (E) MDA-MB-231 cell invasion with different treatments. The cells incubated with 3x10 ${ }^{7}$ PAFactivated platelets were plated in the upper well of Transwell Boyden chamber covered by rat tail collagen, indicated concentrations of DATS and recombinant human TGF- $\beta 1(20 \mathrm{ng} / \mathrm{ml})$ were placed in the upper wells and medium containing $10 \%$ FBS was added into the lower wells. (F) Quantification of the migration and invasion of (D and E) MDA-MB-231 cells. " $\mathrm{P}<0.05$. (G) Western blot analysis of MDA-MB-231 cells for $\mathrm{p}$-smad and total smad in the presence of different treatments. ns, not significant; AP, activated platelets.

chamber assays. Furthermore, the addition of exogenous rTGF- $\beta 1$ resulted in a reversed effect on the inhibition by DATS (Fig. 2C-F). Of note, it was shown that $10 \mu \mathrm{M}$ DATS also suppressed the phosphorylation of Smad, a pivotal molecule of EMT that is closely associated with metastasis, induced by activated platelets and $10 \mathrm{ng} / \mathrm{ml} \mathrm{rTGF}-\beta 1$ reversed this effect (Fig. 2G).

DATS exerts an inhibitory effect on platelet aggregation and activation. To determine whether DATS influences platelet 
A

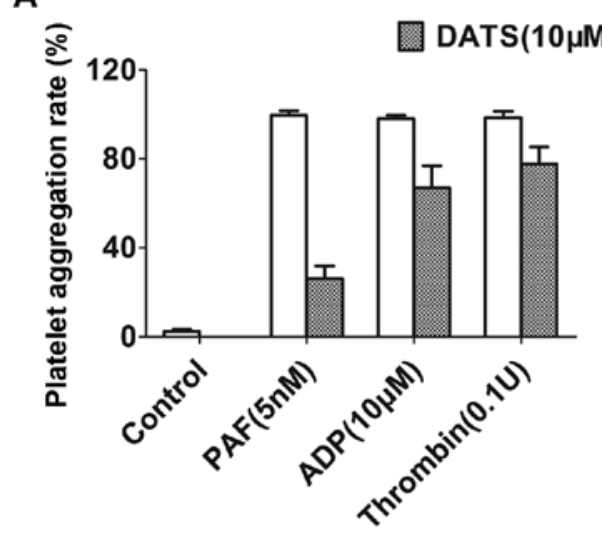

B

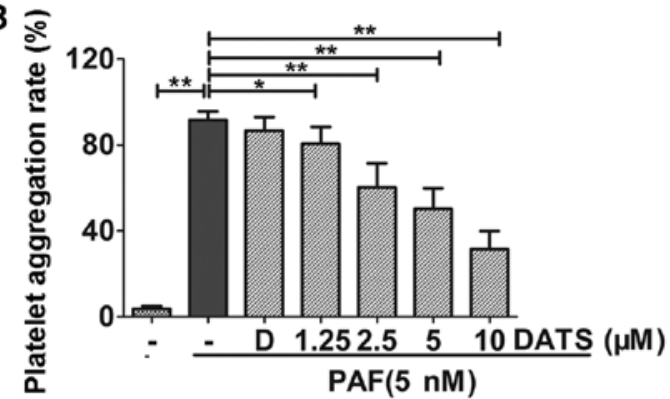

C

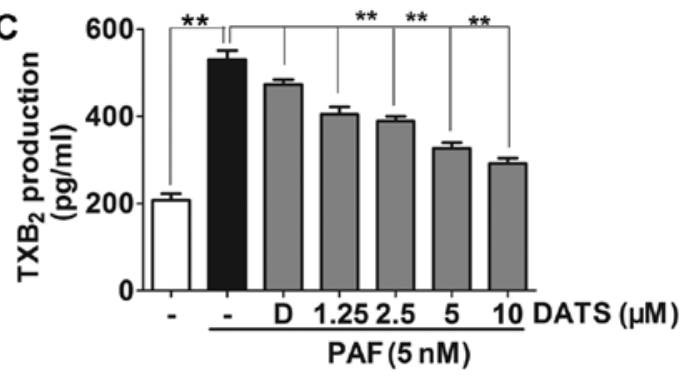

D
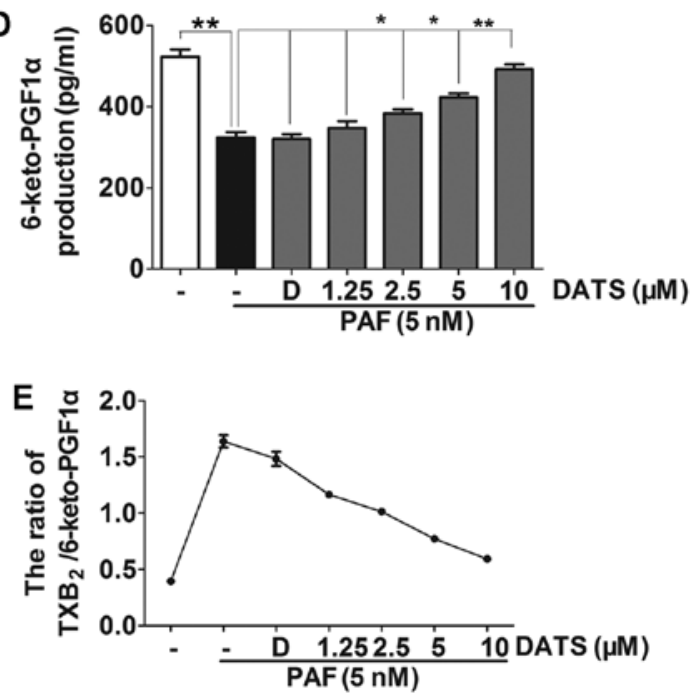

Figure 3. Effect of diallyl trisulfide (DATS) on platelet aggregation. Washed platelets (WP) were incubated with $10 \mu \mathrm{M}$ DATS for 10 min, platelet aggregation induced by platelet-activating factor (PAF) $(5 \mathrm{nM})$, adenosine diphosphate (ADP) $(10 \mu \mathrm{M})$ and thrombin $(0.1 \mathrm{U} / \mathrm{ml})$ was measured with an aggregometer device. (A) Platelets incubated with $10 \mu \mathrm{M}$ DATS significantly neutralize the platelet aggregation stimulated by PAF (5 nM). (B-E) Effects of various concentrations of DATS on radioimmunoassay (RIA) production ( $\mathrm{P}<0.05$ and $\left.{ }^{* *} \mathrm{P}<0.01\right)$. The letter ' $\mathrm{D}$ ' in the $\mathrm{x}$ axes indicates the use of $0.5 \%$ DMSO as the solvent control. The results were presented as the mean value of platelet aggregation from three independently performed experiments. ${ }^{*} \mathrm{P}<0.05$ and ${ }^{* *} \mathrm{P}<0.01$, compared with the control.

function in the blood circulatory system, the platelets were incubated with various concentrations of DATS while being stirred. DATS inhibited platelet aggregation in a dose-dependent manner. Treatments of the cells with 5 and $10 \mu \mathrm{M}$ DATS with the platelets for $10 \mathrm{~min}$ decreased platelet aggregation by 55 and $65 \%$ (Fig. 3A and B), respectively.

Thromboxane $\mathrm{A}_{2}$ (TXA2) and prostacyclin I2 (PGI2) are two metabolites that are associated with platelet activation. An RIA kit was used to examine the effects of DATS on the levels of TXA2 (measured as TXB2), PGI2 (as 6-keto-PGF1 $\alpha$ ) and the thrombogenic ratio (TXB2/6-ketoPGF1 $\alpha$ ) of platelet excreta in human platelets activated by PAF. Significant changes in the levels of TXB2 and 6-ketoPGF1 $\alpha$ and the TXB2/6-keto-PGF1 $\alpha$ ratio were observed in the presence of DATS. DATS significantly reduced the level of TXB2, and increased the level of 6-keto-PGF1 $\alpha$ in a dose-dependent manner, leading to a marked decrease in the TXB2/6-keto-PGF1 $\alpha$ ratio (Fig. 3C-E).

\section{Discussion}

Metastasis is a complex multi-step process involving tumor cell migration and invasion. Accumulating evidence has indicated that hematogenous metastasis is facilitated by tumor cell-platelet emboli formation, and the platelet-tumor cell interaction is considered to be crucial for the process of tumor metastasis (38-40). In addition, it is commonly accepted that blood stasis is highly associated with the progression of tumor metastasis (41). Blood coagulation and tumor malignant biological behaviors interact bidirectionally, by which tumor burden is aggregated to supply more procoagulants and in turn act as strong promoters of cancer growth and spread (42-44).

To enhance the understanding of breast cancer cell metastasis and the role of platelets therein, we established a model in which the malignant biological behaviors of MDA-MB-231 cells can be induced by PAF-activated platelets. In this model, we detected the interaction between platelets and tumor cells and investigated the key factors that mediate tumor cell migration and invasion in a tumor cell-activated platelet system. Various signaling molecules, including TGF- $\beta$, P-selectin, VEGF and angiopoietin that are abundant in platelets, play important roles in modulating tumor cell motility (45-47). In this study, it was found that the release of TGF- $\beta 1$ was markedly increased in the activated platelet-tumor cell system. More importantly, our data indicated that the blockage of TGF- $\beta 1$ resulted in a significant reductions in the malignant biological behaviors of MDA-MB-231 cells. We therefore revealed the fact that TGF- $\beta 1$ is likely to be the critical molecule that mediates the bidirectional interactions between tumor cells and platelets. Given the central role of TGF- $\beta 1$ in the EMT process, 


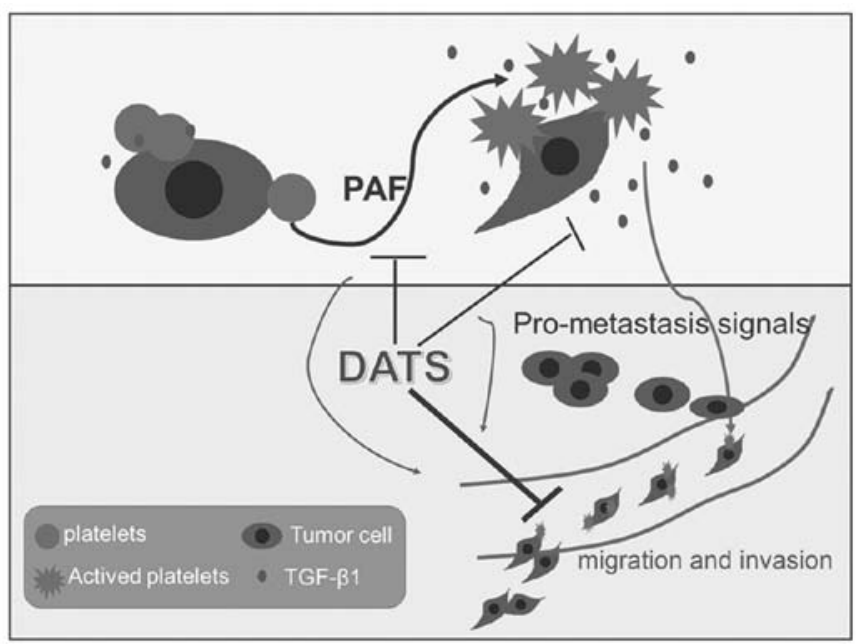

Figure 4. Proposed model of diallyl trisulfide (DATS) treatment which inhibits hematogenous metastasis in breast cancer.

we speculate that the downstream signaling of TGF- $\beta 1$, including the pivotal transcriptional factors Snail and Twist may be influenced accordingly and the balance of $\mathrm{N}$-cadherin and E-cadherin is inclined to be the former in the platelettumor cell system. Collectively, the development of new drugs that not only inhibit the aggregation and activation of platelets, blocking the formation of thrombus, but also suppressing the metastasis of tumor cells is likely to become a novel and potent strategy of anticancer investigation.

Epidemiological and experimental studies have provided evidence in support of the association between garlic intake and reduced cancer risk $(29,48)$. Studies over the past decade have also shown that garlic has a specific activity in treating cardiovascular diseases (49), and the effect correlates with the inhibition of platelet activation in the circulatory system (50). We thus attempted to elucidate the effects of a series of garlic organic sulfides (DAS/DADS/DATS) on the activated platelet-induced metastasis of MDA-MB-231 human breast cancer cells. DATS is a lipo-soluble compound from garlic extract with the most sulfur atoms and has been proven to be the most effective compound among these garlic organic sulfides. Our results revealed that DATS rather than the other two organic sulfides decreased the release of TGF- $\beta 1$ at $10 \mu \mathrm{M}$ in the platelet-tumor cell system. We postulated that the sulfur atoms may be the critical functional group for the antitumor effects of garlic organic sulfides, which still requires further confirmation. Of note, a potential study to address the effect of sulfur atom in tumor progress and platelet activities can be proposed by synthesizing compounds composed of different numbers of sulfur atoms. The effects of these compounds on an array of tumor malignant biological behaviors, including proliferation, migration and invasion can be evaluated in the presence of activated platelets.

As a lipophilic compound extracted from garlic, DATS has been shown to be a novel anticancer agent. Numerous studies have indicated that DATS has strong anti-proliferative and pro-apoptotic activities in many cell lines (51-53). DATS-rich garlic oil benefits blood anti-coagulation factors and further prevents the development of thrombus. DATS also exhibited the greatest inhibitory effect on ADP-induced platelet aggregation compared to the other two organic sulfides in our study. Of note, the $\mathrm{P} 2 \mathrm{Y}_{12}$ receptor, activated by ADP, exerts great influence on platelet activation by inducing a number of intracellular signaling events downstream of the $\mathrm{G}_{\mathrm{i}}$ pathway that contribute to fibrinogen receptor activation. Given the inhibition of ADP-induced platelet aggregation by DATS, it is reasonable to detect $\mathrm{P} 2 \mathrm{Y}_{12}$-mediated downstream signaling in the future. Moreover, since thrombin-induced platelet activation involves the cleavage of protease-activated receptors (PARs) 1 and 4, it may be also worthwhile examining whether DATS can regulate PAR signaling pathways, which may provide us with more detailed indications of the DATSmediated inhibitory effect on platelet activation. Notably, the present study demonstrateed that $10 \mu \mathrm{M}$ is an effective dose for DATS, which is consistent with previous studies (54-56). The results of dose-response experiments of DATS on platelet activation and aggregation (data not shown) also confirmed the effective consumption of garlic to show the impact on platelets.

Collectively, our study has indicated that DATS can act both on platelets and tumor cells, and it exerts great influence on platelet activities, including reducing platelet activation and aggregation induced by PAF. It also plays a significant role in diminishing the release of TGF- $\beta 1$ from tumor cells, which can be recognized as the critical step for tumor hematogenous metastasis (Fig. 4). This observation is of great importance due to the fact that tumor progression and platelet aggregation form a vicious circle in the process of their interactions. They produce synergistic malignant effects in hematogenous metastasis, which incurs increased difficulties in the treatment of cancer. To this end, DATS acts as a potent compound that targets both tumor cells and platelet activation and aggregation, which to a certain extent indicates an effective method with which to prevent tumor progression and limit the interactions between tumor cells and platelets. Taken together, our study provides definitive evidence that DATS plays a pivotal role in decreasing platelet activities and reveals a novel mechanism of this garlic ingredient in inhibiting tumor hematogenous metastasis.

\section{Acknowledgements}

This study was supported by the National Natural Science Foundation of China (nos. 81173174 and 81202655), National Key Technology Research and Development Program (no. 2008BAI51B02), Ph.D. Programs Foundation of Ministry of Education of China (no. 20113237110008), Chinese Postdoctoral Science Foundation (2014M551639), Postdoctoral Science Foundation of Jiangsu Province (1401138C), Doctoral Innovation Project of Jiangsu Province (KYLX_0977) and Jiangsu College Graduate Research and Innovation Projects (no. KYLX_0977; CXZZ13_0627). The funders had no role in study design, data collection and analysis, decision to publish, or preparation of the manuscript.

\section{References}

1. Zhang XH: Why cancer cells metastasize? Med Hypotheses 80: 669-671, 2013.

2. Labelle M and Hynes RO: The initial hours of metastasis: the importance of cooperative host-tumor cell interactions during hematogenous dissemination. Cancer Discov 2: 1091-1099, 2012. 
3. Mezouar S, Mege D, Darbousset R, Farge D, Debourdeau P, Dignat-George F, Panicot-Dubois L and Dubois C: Involvement of platelet-derived microparticles in tumor progression and thrombosis. Semin Oncol 41: 346-358, 2014.

4. Stravodimou A and Voutsadakis IA: Pretreatment thrombocytosis as a prognostic factor in metastatic breast cancer. Int J Breast Cancer 2013: 289563, 2013.

5. Wang PL, Cheng YB and Kuerban G: The clinical characteristic differences between thrombosis-related edema and lymphedema following radiotherapy or chemoradiotherapy for patients with cervical cancer. J Radiat Res (Tokyo) 53: 125-129, 2012.

6. Holmes CE,Levis JE and Ornstein DL: Activated platelets enhance ovarian cancer cell invasion in a cellular model of metastasis. Clin Exp Metastasis 26: 653-661, 2009.

7. Zhu JF, Cai L, Zhang XW, Wen YS, Su XD, Rong TH and Zhang LJ: High plasma fibrinogen concentration and platelet count unfavorably impact survival in non-small cell lung cance patients with brain metastases. Chin J Cancer 33: 96-104, 2014.

8. Gupta GP and Massagué J: Platelets and metastasis revisited: a novel fatty link. J Clin Invest 114: 1691-1693, 2004.

9. Smith AL, Robin TP and Ford HL: Molecular pathways: targeting the TGF- $\beta$ pathway for cancer therapy. Clin Cancer Res 18 : 4514-4521, 2012

10. Perera M, Tsang CS, Distel RJ, Lacy JN, Ohno-Machado L, Ricchiuti V, Samaranayake LP, Smejkal GB, Smith MG Trachtenberg AJ, et al: TGF-beta1 interactome: metastasis and beyond. Cancer Genomics Proteomics 7: 217-229, 2010.

11. Ma J, Gao HM, Hua X, Lu ZY and Gao HC: Role of TGF- $\beta 1$ in human colorectal cancer and effects after cantharidinate intervention. Asian Pac J Cancer Prev 15: 4045-4048, 2014.

12. Hyytiäinen M, Penttinen C and Keski-Oja J: Latent TGF-beta binding proteins: extracellular matrix association and roles in TGF-beta activation. Crit Rev Clin Lab Sci 41: 233-264, 2004.

13. Meindl-Beinker NM, Matsuzaki K and Dooley S: TGF- $\beta$ signaling in onset and progression of hepatocellular carcinoma. Dig Dis 30: 514-523, 2012.

14. Bakkebø M, Huse K, Hilden VI, Smeland EB and Oksvold MP. TGF- $\beta$-induced growth inhibition in B-cell lymphoma correlates with Smad1/5 signalling and constitutively active p38 MAPK. BMC Immunol 11: 57, 2010.

15. Binker MG, Binker-Cosen AA, Gaisano HY, de Cosen RH and Cosen-Binker LI: TGF- $\beta 1$ increases invasiveness of SW1990 cells through Rac1/ROS/NF- $\mathrm{kB} / \mathrm{IL}-6 / \mathrm{MMP}-2$. Biochem Biophys Res Commun 405: 140-145, 2011.

16. Morita T, Mayanagi T and Sobue K: Dual roles of myocardinrelated transcription factors in epithelial mesenchymal transition via slug induction and actin remodeling. J Cell Biol 179: $1027-1042,2007$

17. Wilkins-Port CE, Higgins SP, Higgins CE, Kobori-Hotchkiss I and Higgins PJ: Complex regulation of the pericellular proteolytic microenvironment during tumor progression and wound repair: functional interactions between the serine protease and matrix metalloproteinase cascades. Biochem Res Int 2012: 454368, 2012.

18. Hawinkels LJ, Verspaget HW, van der Reijden JJ, van der Zon JM, Verheijen JH, Hommes DW, Lamers CB and Sier CF: Active TGF-beta1 correlates with myofibroblasts and malignancy in the colorectal adenoma-carcinoma sequence. Cancer Sci 100: 663-670, 2009

19. Donovan MJ and Cordon-Cardo C: Genomic analysis in active surveillance: predicting high-risk disease using tissue biomarkers. Curr Opin Urol 24: 303-310, 2014

20. Joseph JV, Balasubramaniyan V, Walenkamp A and Kruyt FA: TGF- $\beta$ as a therapeutic target in high grade gliomas - promises and challenges. Biochem Pharmacol 85: 478-485, 2013.

21. Han H, Cao FL, Wang BZ, Mu XR, Li GY and Wang XW: Expression of angiogenesis regulatory proteins and epithelialmesenchymal transition factors in platelets of the breast cancer patients. ScientificWorldJournal 2014: 878209, 2014

22. Pak KH, Kim DH, Kim H, Lee do H and Cheong JH: Differences in TGF- $\beta 1$ signaling and clinicopathologic characteristics of histologic subtypes of gastric cancer. BMC Cancer 16: 60, 2016.

23. Surh YJ and Ferguson LR: Dietary and medicinal antimutagens and anticarcinogens: molecular mechanisms and chemopreventive potential - highlights of a symposium. Mutat Res 523-524: $1-8,2003$

24. Mousa SA: Antithrombotic effects of naturally derived products on coagulation and platelet function. Methods Mol Biol 663: 229-240, 2010

25. Chan KC, Yin MC and Chao WJ: Effect of diallyl trisulfide-rich garlic oil on blood coagulation and plasma activity of anticoagulation factors in rats. Food Chem Toxicol 45: 502-507, 2007.
26. Khatua TN, Adela R and Banerjee SK: Garlic and cardioprotection: insights into the molecular mechanisms. Can J Physiol Pharmacol 91: 448-458, 2013.

27. Allison GL, Lowe GM and Rahman K: Aged garlic extract and its constituents inhibit platelet aggregation through multiple mechanisms. J Nutr 136 (Suppl 3): 782S-788S, 2006.

28. Rahman K and Billington D: Dietary supplementation with aged garlic extract inhibits ADP-induced platelet aggregation in humans. J Nutr 130: 2662-2665, 2000

29. Trio PZ, You S, He X, He J, Sakao K and Hou DX: Chemopreventive functions and molecular mechanisms of garlic organosulfur compounds. Food Funct 5: 833-844, 2014

30. Chandra-Kuntal K, Lee J and Singh SV: Critical role for reactive oxygen species in apoptosis induction and cell migration inhibition by diallyl trisulfide, a cancer chemopreventive component of garlic. Breast Cancer Res Treat 138: 69-79, 2013.

31. Li Y, Zhang J, Zhang L, Si M, Yin H and Li J: Diallyl trisulfide inhibits proliferation, invasion and angiogenesis of osteosarcoma cells by switching on suppressor microRNAs and inactivating of Notch-1 signaling. Carcinogenesis 34: 1601-1610, 2013.

32. Lai KC, Hsu SC, Kuo CL, Yang JS, Ma CY, Lu HF, Tang NY, Hsia TC, Ho HC and Chung JG: Diallyl sulfide, diallyl disulfide, and diallyl trisulfide inhibit migration and invasion in human colon cancer colo 205 cells through the inhibition of matrix metalloproteinase-2, -7, and -9 expressions. Environ Toxicol 28: 479-488, 2013.

33. Singh SV, Powolny AA, Stan SD, Xiao D, Arlotti JA, Warin R, Hahm ER, Marynowski SW, Bommareddy A, Potter DM and Dhir R: Garlic constituent diallyl trisulfide prevents development of poorly differentiated prostate cancer and pulmonary metastasis multiplicity in TRAMP mice. Cancer Res 68: 9503-9511, 2008.

34. Xiao D, Herman-Antosiewicz A, Antosiewicz J, Xiao H, Brisson M, Lazo JS and Singh SV: Diallyl trisulfide-induced G(2)-M phase cell cycle arrest in human prostate cancer cells is caused by reactive oxygen species-dependent destruction and hyperphosphorylation of Cdc $25 \mathrm{C}$. Oncogene 24: 6256-6268, 2005.

35. Shankar S, Chen Q, Ganapathy S, Singh KP and Srivastava RK: Diallyl trisulfide increases the effectiveness of TRAIL and inhibits prostate cancer growth in an orthotopic model: molecular mechanisms. Mol Cancer Ther 7: 2328-2338, 2008.

36. Powolny AA and Singh SV: Multitargeted prevention and therapy of cancer by diallyl trisulfide and related Allium vegetable-derived organosulfur compounds. Cancer Lett 269: 305-314, 2008.

37. Ng KT, Guo DY, Cheng Q, Geng W, Ling CC, Li CX, Liu XB, Ma YY,LoCM,Poon RT, et al: A garlic derivative, S-allylcysteine (SAC), suppresses proliferation and metastasis of hepatocellular carcinoma. PLoS One 7: e31655, 2012.

38. Belloc C, Lu H, Soria C, Fridman R, Legrand Y and Menashi S: The effect of platelets on invasiveness and protease production of human mammary tumor cells. Int J Cancer 60: 413-417, 1995.

39. Nierodzik ML, Plotkin A, Kajumo F and Karpatkin S: Thrombin stimulates tumor-platelet adhesion in vitro and metastasis in vivo. J Clin Invest 87: 229-236, 1991.

40. Jurasz P, Alonso-Escolano D and Radomski MW: Platele-cancer interactions: mechanisms and pharmacology of tumour cell-induced platelet aggregation. Br J Pharmacol 143: 819-826, 2004.

41. Qian $Y F$ and Wang XJ: Effects of blood-activating and stasis-resolving drugs on tumor formation and metastasis. J Tradit Chin Med 29: 301-310, 2009.

42. Gil-Bernabé AM, Ferjancic S, Tlalka M, Zhao L, Allen PD, Im JH, Watson K, Hill SA, Amirkhosravi A, Francis JL, et al: Recruitment of monocytes/macrophages by tissue factor-mediated coagulation is essential for metastatic cell survival and premetastatic niche establishment in mice. Blood 119: 3164-3175, 2012.

43. Im JH, Fu W, Wang H, Bhatia SK, Hammer DA, Kowalska MA and Muschel RJ: Coagulation facilitates tumor cell spreading in the pulmonary vasculature during early metastatic colony formation. Cancer Res 64: 8613-8619, 2004.

44. McEachron TA, Pawlinski R, Richards KL, Church FC and Mackman N: Protease-activated receptors mediate crosstalk between coagulation and fibrinolysis. Blood 116: 5037-5044,2010.

45. Battinelli EM, Markens BA and Italiano JE Jr: Release of angiogenesis regulatory proteins from platelet alpha granules: modulation of physiologic and pathologic angiogenesis. Blood 118: 1359-1369, 2011

46. Hara T, Shimizu K, Ogawa F, Yanaba K, Iwata Y, Muroi E, Takenaka M, Komura K, Hasegawa M, Fujimoto M, et al: Platelets control leukocyte recruitment in a murine model of cutaneous arthus reaction. Am J Pathol 176: 259-269, 2010. 
47. Xu L, Tong R, Cochran DM and Jain RK: Blocking platelet-derived growth factor-D/platelet-derived growth factor receptor beta signaling inhibits human renal cell carcinoma progression in an orthotopic mouse model. Cancer Res 65: 5711-5719, 2005.

48. Fleischauer AT and Arab L: Garlic and cancer: a critical review of the epidemiologic literature. J Nutr 131: 1032S-1040S, 2001.

49. Ginter E and Simko V: Garlic (Allium sativum L.) and cardiovascular diseases. Bratisl Lek Listy 111: 452-456, 2010.

50. Allison GL, Lowe GM and Rahman K: Aged garlic extract inhibits platelet activation by increasing intracellular cAMP and reducing the interaction of GPIIb/IIIa receptor with fibrinogen. Life Sci 91: 1275-1280, 2012.

51. Li W, Tian H, Li L, Li S, Yue W, Chen Z, Qi L, Hu W, Zhu Y, Hao B, et al: Diallyl trisulfide induces apoptosis and inhibits proliferation of A549 cells in vitro and in vivo. Acta Biochim Biophys Sin (Shanghai) 44: 577-583, 2012.

52. Watanabe K, Hosono T, Watanabe K, Hosono-Fukao T, Ariga T and Seki T: Diallyl trisulfide induces apoptosis in Jurkat cells by the modification of cysteine residues in thioredoxin. Biosci Biotechnol Biochem 78: 1418-1420, 2014
53. Ma HB, Huang S, Yin XR, Zhang Y and Di ZL: Apoptotic pathway induced by diallyl trisulfide in pancreatic cancer cells. World J Gastroenterol 20: 193-203, 2014.

54. Sakamoto K, Lawson LD and Milner JA: Allyl sulfides from garlic suppress the in vitro proliferation of human A549 lung tumor cells. Nutr Cancer 29: 152-156, 1997.

55. Li J, Liu W, Zhao K, Zhang Y, Li X, Yang Q, Li Z and Li J: Diallyl trisulfide reverses drug resistance and lowers the ratio of $\mathrm{CD} 133^{+}$ cells in conjunction with methotrexate in a human osteosarcoma drug-resistant cell subline. Mol Med Rep 2: 245-252, 2009.

56. Tsai CY, Wang CC, Lai TY, Tsu HN, Wang CH, Liang HY and Kuo WW: Antioxidant effects of diallyl trisulfide on high glucose-induced apoptosis are mediated by the PI3K/Akt-dependent activation of Nrf2 in cardiomyocytes. Int J Cardiol 168: 1286-1297, 2013. 